\title{
Lung Manifestation of Collagen Vascular Disease in HRCT
}

\author{
Jagruti Kalola ${ }^{\circledR 1}$, Anjana Trivedi ${ }^{2}$, Hiral Happani ${ }^{\circledR 3}$, Mohit Chauhan ${ }^{\circledR 4}$ \\ ${ }^{1}$ Additional Professor, Department of Radio diagnosis, PDU Medical College\& Government Hospital, Rajkot, Gujarat, India, ${ }^{2}$ Professor and Head, Department of Radio \\ diagnosis, PDU Medical College\& Government Hospital, Rajkot, Gujarat, India, ${ }^{3}$ Assistant Professor, Department of Radio diagnosis, PDU Medical College \& Government \\ Hospital, Rajkot, Gujarat, India, ${ }^{4}$ Resident Doctor, Department of Radio diagnosis, PDU Medical College\& Government Hospital, Rajkot, Gujarat, India.
}

\section{Abstract}

Background: The aim of this paper was to evaluate the thoracic manifestations associated with the Connective tissue disorders, with an emphasis on interstitial and airway disease pattern on the High Resolution computed tomography (HRCT) findings. Subjects and Methods: The present study was conducted for a period of one year. A total of 50 patients with various connective tissue disorders having respiratory complaints were evaluated. Results: During the study period 50 patients ( $80 \%$ females and $20 \%$ males) underwent evaluation. Cough and dyspnea were the most common presenting symptoms. Variety of thoracic abnormalities weredetected in 67 (95\%) cases. Most common abnormality detected on HRCT was interstitial fibrosis/interstitial lung disease present in (60\%) cases. Most common parenchymal abnormalities seen were reticulations (61.4\%), ground glass opacification (40\%), mosaic attenuation (32.8\%) and honeycombing (24.3\%). Airway abnormalities seen were bronchiectasis (48.5\%), emphysema (12.8\%), and ground glass nodules $(2.8 \%)$. Conclusion: Interstitial lung disease is the most common pulmonary manifestation among patients with connective tissue disorders, and early detection and prompt treatment is expected to improve the outcome.

Keywords: Connective Tissue Disorders, Thoracic Manifestations, Interstitial Lung Disease.

Corresponding Author: Jagruti Kalola, Additional Professor, Department of Radio diagnosis, PDU Medical College\& Government Hospital, Rajkot, Gujarat, India.

E-mail: sutariajagruti@gmail.com

Received: 22 December 2019

Revised: 02 February 2020

Accepted: 08 February 2020

Published: 29 April 2020

\section{Introduction}

Interstitial lung disease (ILD) is a group of diffuse parenchymal lung diseases affecting the pulmonary interstitium. ${ }^{[1]}$

High resolution computed tomography is the most accurate, noninvasive, cross section imaging modality for the diagnosis and follow up monitoring of ILD. ${ }^{[2-4]}$

This Study was done to check the basic HRCT patterns associated with Interstitial Lung Disease and correlation of HRCT patterns with clinical data in differential diagnosis of Interstitial Lung Disease. ${ }^{[5,6]}$

\section{Aims \& Objectives}

- Identify clinical manifestations of thoracic involvement in collagen vascular disease.

- Recognize interstitial lung disease patterns and other thoracic imaging features specific to collagen vascular diseases that often affect the respiratory system.

\section{Subjects and Methods}

\section{Methodology}

Sample size $=50$

Study design $=$ Prospective study

Type of study $=$ Single centre

Duration of study=1yr (from October 2018 to September 2019)

Place of study=PDU Medical college \& govt. hospital, Rajkot

Consent for participation in study $=$ Yes

\section{Patient Selection}

\section{Inclusion Criteria}

Patients referred from medicine or skin department of our Radiology department having clinical suspicion of ILD.

\section{Exclusion Criteria}

Known cases of infective etiology (Tuberculosis, HIV), chronic obstructive pulmonary disease, congestive cardiac 
failure, lung malignancy, hemodynamically unstable patients.

\section{Machine Used}

\section{- GE 16 slice CT scanner using HRCT protocol}

Consent for participation in the study will be taken from the patient.

The indication and details of the CT scan procedure explained to patient.

Written consent will be obtained either from patient or his/her relatives for $\mathrm{CT}$ scan

Observations will be recorded in patient proformas and analysed statistically.

Parenchymal abnormalities were categorized into four basic patterns of HRCT with their distribution and predominant involvement. Final possible diagnosis was made as per HRCT findings and clinical information.

\section{Results}

Out of 50 patients $(80 \%$ females, $20 \%$ males with a mean age of 42.6 years), $56 \%$ had respiratory symptoms. Scleroderma was the most common disease $(38.6 \%)$ followed by rheumatoid arthritis (26.6\%) and systemic lupus erythematosus (14.6\%). Interstitial tissue involvement of the lung was the most frequent finding in patients with scleroderma, dermatomyositis, polymyositis and Sjogren's syndrome (48.3\%, $57.1 \%, 60 \%$ and $66.7 \%$, respectively). Pleural thickening was the most common finding in patients with rheumatoid arthritis $(45 \%)$. Pleural effusion was the most frequent finding in patients with systemic lupus erythematosus (45.4\%). Lymphadenopathy and bronchiectasis had the lowest prevalence $(1.3 \%)$.

\section{Discussion}

Involvement of the respiratory system is common in the collagen vascular diseases and results in significant morbidity and mortality. Lung injury from collagen vascular disease can affect each portion of the lung, commonly; more than one compartment. Although there is some overlap, each collagen vascular disease is associated with a characteristic pattern of pulmonary involvement. The lung disease in these cases may precede the clinical presentation of the collagen disease, sometimes by more than five years.

HRCT is the imaging technique of choice for evaluation of patients with connective tissue diseases, demonstrating the presence, gross characteristics and distribution of pulmonary disease with greater sensitivity than conventional chest radiographs. In certain clinical circumstances, HRCT findings

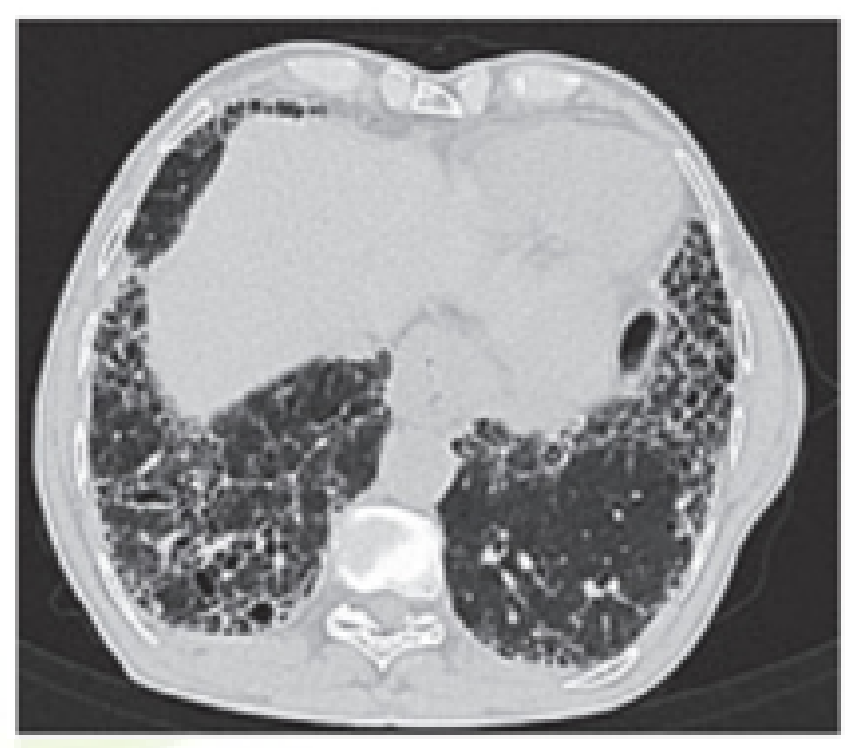

Figure 1: HRCT Shows bilateral diffuse extensive fibrosis with septal thickening, honeycombing, traction bronchiectasis predominantly involving bilateral lower lobs in sub pleural region and architectural distortion resulting in reduced lung volume. Findings are in favour of usual interstitial pneumonia/idiopathic pulmonary fibrosis.

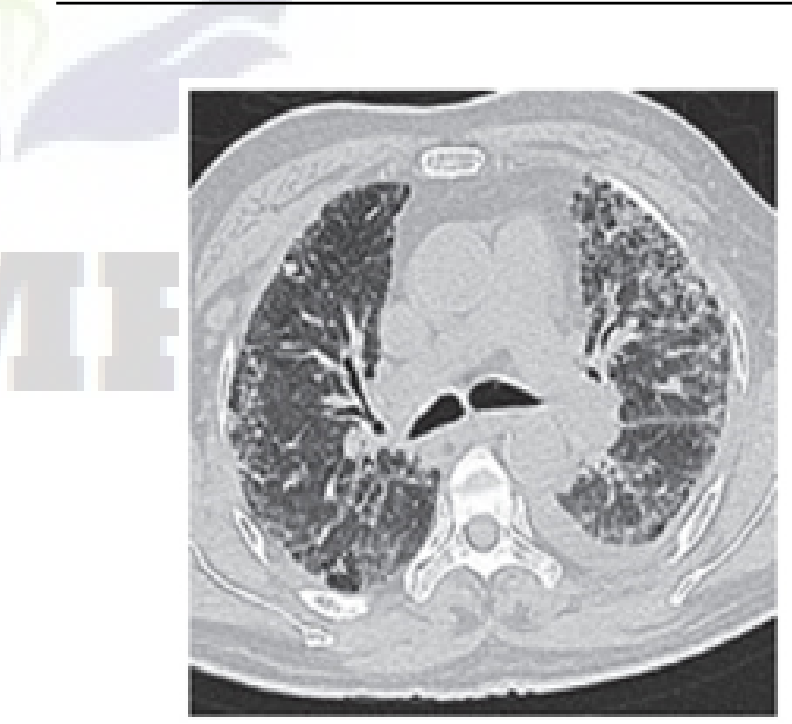

Figure 2: HRCT shows bilateral diffuse Interstitial lung disease in the form of interlobular and intralobular septal thickening predominantly in sub pleural region with focal areas of tiny honeycombing with left sided pleural effusion. Findings are in favour of idiopathic interstitial pneumonianonspecific interstitial pneumonia.

can suggest a specific diagnostic process. HTCT often 


\begin{tabular}{llll}
\hline Table 1: Gender of patients & & & Total \\
\hline Disease & Female & Male & 18 \\
\hline RA & 13 & 5 & 9 \\
\hline SLE & 8 & 1 & 2 \\
\hline Sjogren's syndrome & 2 & 0 & 6 \\
\hline Dermatomyositis & 5 & 1 & 4 \\
\hline Polymyositis & 2 & 2 & 11 \\
\hline Scleroderma & 10 & 1 & 50 \\
\hline Total & 40 & 10 & \\
\hline RA=
\end{tabular}

$\mathrm{RA}=$ rheumatoid arthritis, $\mathrm{SLE}=$ systemic lupus erythematous

\begin{tabular}{|c|c|c|c|c|c|c|c|}
\hline HRCT findings & RA & SLE & $\begin{array}{l}\text { Sjogren's } \\
\text { Syndrome }\end{array}$ & Dermatomyositis & Polymyositis & Scleroderma & Total \\
\hline ILD & 5 & 2 & 1 & 3 & 3 & 6 & 20 \\
\hline Pleural fibrosis & 7 & 0 & 1 & 2 & 0 & 3 & 13 \\
\hline Consolidation & 4 & 2 & 0 & 1 & 0 & 2 & 9 \\
\hline $\begin{array}{l}\text { Pleural effu- } \\
\text { sion }\end{array}$ & 0 & 4 & 0 & 0 & 0 & 0 & 4 \\
\hline Cardiomegaly & 0 & 1 & 0 & 0 & 1 & 0 & 2 \\
\hline $\begin{array}{l}\text { Lymphadeno- } \\
\text { pathy }\end{array}$ & 1 & 0 & 0 & 0 & 0 & 0 & 1 \\
\hline Bronchiectasis & 1 & 0 & 0 & 0 & 0 & 0 & 1 \\
\hline Total & 18 & 9 & 2 & 6 & 4 & 11 & 50 \\
\hline
\end{tabular}

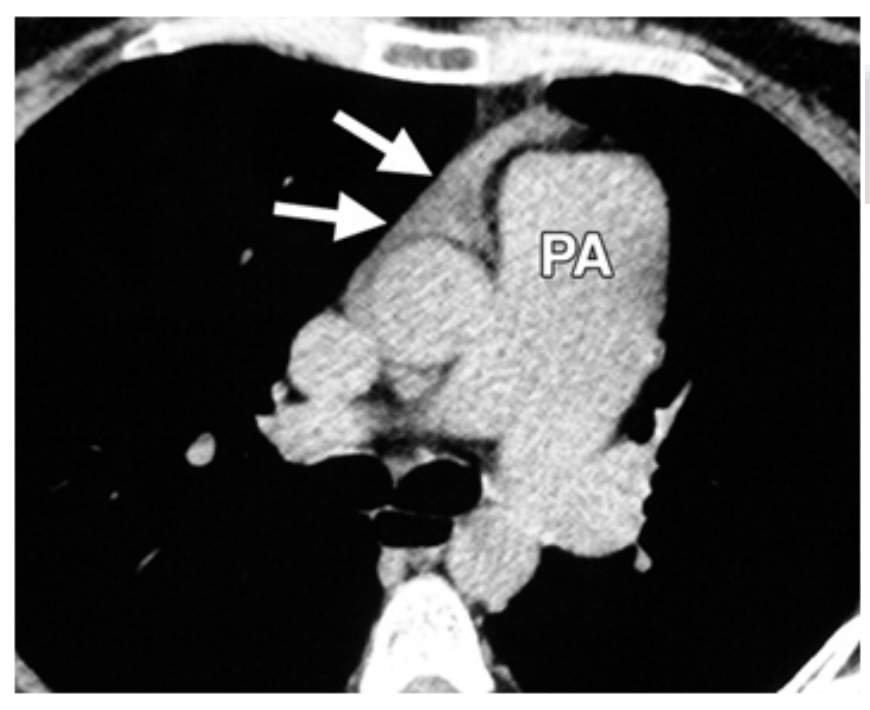

Figure 3: Pulmonary hypertension in a 27-year-old woman with progressive systemic sclerosis. Unenhanced axial CT image depicts enlargement of the pulmonary artery (PA) trunk and a substantial amount of pericardial effusion (arrows) in the anterior superior aortic recess. allows the predominant process to be identified. However, it has some limitations. In many cases, HRCT appearance is nonspecific and may or may not be related to an underlying CTD. Thus, radiologic findings should never be interpreted without knowledge of the clinical picture. The best approach to evaluate connective tissue disease is to recognize and analyze different patterns of involvement, which include pulmonary, pleural and mediastinal or hilar lymph node involvement. Interstitial lung disease (ILD) is a challenging clinical entity that can be associated with multiple CTDs. The term ILD is used to describe heterogeneous disorders of the lungs that share common radiologic, pathologic, and clinical manifestations. In addition to ILD, other forms of lung damage involving the vasculature, airways, and lymphatic tissues can complicate connective tissue disease. Linear and reticular opacities are among the most important CT findings in connective tissue disease. Reticular pattern represents thickening of the interlobular interstitium within the secondary pulmonary lobule. In end stage disease, honeycomb pattern may be seen and represents terminal lung disease. Other patterns of pulmonary involvement include nodular opacities, ground glass opacities, air space consolidation and decreased lung opacity such as in emphysema. 


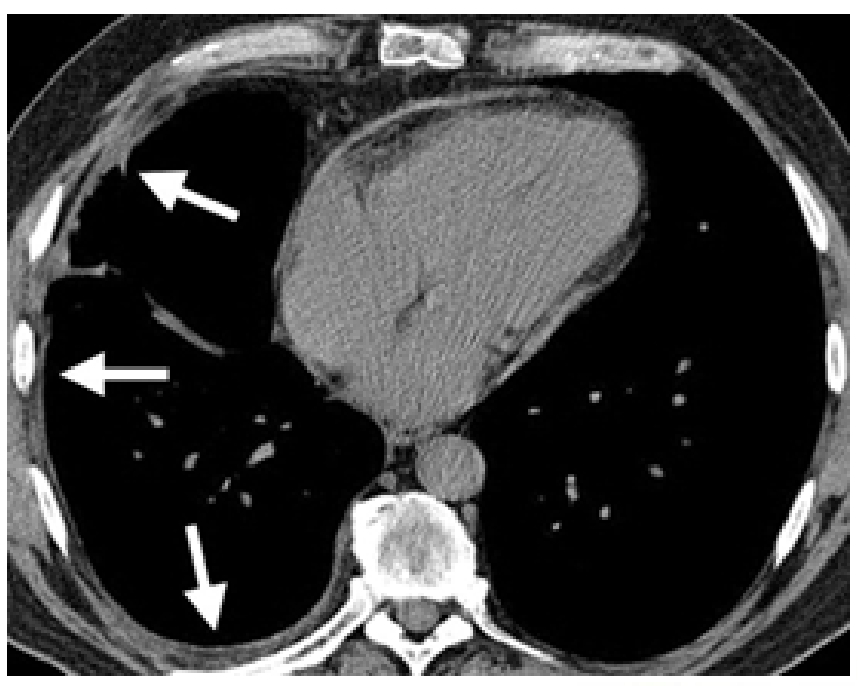

Figure 4: Axial unenhanced CT image obtained in a 58-year-old man with rheumatoid arthritis shows diffuse right pleural thickening with a small amount of pleural effusion (arrows). Diffuse thickening of the pericardium is also seen. High-resolution CT images (not shown) obtained with lung window settings showed no substantial pulmonary abnormalities .

Rheumatoid arthritis (RA) is the most common type of CTD, affecting about $1 \%$ of people worldwide. The frequency of pulmonary abnormalities found in association with RA has been shown to vary widely. Pleural involvement, pleural fibrosis is the most common thoracic manifestation of RA. The degree of interstitial lung involvement does not necessarily correlate with the severity of articular involvement. The radiographic findings are often subtle and chest radiographs may be normal or show only honeycombing opacities $=$.

Systemic lupus erythematosus (SLE) is associated with pleuropulmonary disease in more than half the patients. Pleural effusion is the most common thoracic manifestation of SLE. SLE is not commonly associated with chronic diffuse ILD.

ILD is the most common complication of scleroderma, occurring in up to $55 \%$ of cases. The HRCT findings of interstitial fibrosis in scleroderma include ground glass attenuation, subpleural reticular opacities, traction bronchiectasis, architectural distortion, pleural thickening or effusion, and centrilobular micronodules in a predominantly peripheral and basilar distribution.

Pleural thickening was the most common finding in patients with RA in our study, but in Mohd Noor et al's study reticulation followed by ground glass opacities was the most common HRCT findings. In Zrour's study, interstitial involvement had the highest frequency in RA patients $(28 \%)$. These differences may be due to variable ethnicity, disease activity and duration of disease in patients.

We showed that pleural effusion was the most frequent finding in patients with SLE which is in contrast to Fenlon et al's findings. ${ }^{\text {[7] }}$ This may be due to the variable severity of systemic lupus erythematosus in patients. We studied patients admitted to hospital but they worked on outpatients suffering from SLE.

In our patients with scleroderma, interstitial tissue involvement was the most common finding similar to Goldin et al's study. ${ }^{[8]}$ In patients with polymyositis and dermatomyositis, interstitial tissue involvement was the most common finding similar to Ikezoe et al's study. ${ }^{[9]}$

In Sjogren's syndrome, interstitial involvement was the most common finding in our study which is in accord with Koyama et al study. ${ }^{[10]}$

Our study had several limitations. We did not evaluate the duration of disease, history of smoking or disease activity or severity in our patients because of incomplete patient records.

In conclusion, the most frequent HRCT finding in patients with connective tissue disease was interstitial tissue involvement.

\section{Conclusion}

From this study it is evident that thoracic organs are frequent targets of immune- mediated injury in CTDs. Any thoracic compartment (parenchyma, airway, pleura and mediastinum) can be affected; however, the most important manifestation is interstitial lung disease. HRCT is the diagnostic modality for early detection which can help in prompt treatment for better prognosis.

\section{References}

1. Bouros D, Pneumatikos I, Tzouvelekis A. Pleural Involvement in Systemic Autoimmune Disorders. Respiration. 2008;75(4):361-371. Available from: https://dx.doi.org/10. 1159/000119051.

2. Woodhead F, Wells AU, Desai SR. Pulmonary Complications of Connective Tissue Diseases. Clin Chest Med. 2008;29(1):149-164. Available from: https://dx.doi.org/10. 1016/j.ccm.2007.11.009.

3. Mayberry JP, Primack SL, Müller NL. Thoracic Manifestations of Systemic Autoimmune Diseases: Radiographic and High-Resolution CT Findings. RadioGraphics. 2000;20(6):1623-1635. Available from: https://dx.doi.org/10.1148/radiographics.20.6.g00nv031623.

4. Afeltra A, Zennaro D, Garzia P, Gigante A, Vadacca M, Ruggiero A, et al. Prevalence of interstitial lung involvement in patients with connective tissue diseases assessed with high-resolution computed tomography. Scand J Rheumatol. 2006;35(5):388-394. Available from: https://dx.doi.org/10. 1080/03009740600844381. 
5. Noor NM, Shahrir MSM, Shahid MS, Manap RA, Azura AMS, Shah SA. Clinical and high resolution computed tomography characteristics of patients with rheumatoid arthritis lung disease. Int J Rheum Dis. 2009;12(2):136-144. Available from: https://dx.doi.org/10.1111/j.1756-185x.2009.01376.x

6. Zrour SH, Touzi M, Bejia I, Golli M, Rouatbi N, Sakly N. Correlations between high-resolution computed tomography of the chest and clinical function in patients with rheumatoid arthritis. Prospective study in 75 patients. Joint Bone Spine. 2005;72(1):41-48. Available from: https://doi.org/10.1016/j. jbspin.2004.02.001.

7. Fenlon HM, Doran M, Sant SM, Breatnach E. High-resolution chest CT in systemic lupus erythematosus. Am J Roentgenol. 1996;166(2):301-307. Available from: https://doi.org/10. 2214/ajr.166.2.8553934.

8. Goldin JG, Lynch DA, Strollo DC, Suh RD, Schraufnagel DE, Clements PJ, et al. High-Resolution CT Scan Findings in Patients With Symptomatic Scleroderma-Related Interstitial Lung Disease. Chest. 2008;134(2):358-367. Available from: https://dx.doi.org/10.1378/chest.07-2444.

9. Ikezoe J, Johkoh $\mathrm{T}$, Kohno N, Takeuchi N, Ichikado K, Nakamura H. High-Resolution CT Findings of Lung Disease in Patients with Polymyositis and Dermatomyositis. J Thorac
Imaging. 1996;11(4):250-259. Available from: https://dx.doi. org/10.1097/00005382-199623000-00002.

10. Koyama M, Johkoh T, Honda O, Mihara N, Kozuka T, Tomiyama N. Pulmonary involvement in primary Sjögren's syndrome: spectrum of pulmonary abnormalities and computed tomography findings in 60 patients. J Thorac Imaging. 2001;16(4):290-296. Available from: https://doi.org/10.1097/ 00005382-200110000-00010.

Copyright: (C) the author(s), 2020. It is an open-access article distributed under the terms of the Creative Commons Attribution License (CC BY 4.0), which permits authors to retain ownership of the copyright for their content, and allow anyone to download, reuse, reprint, modify, distribute and/or copy the content as long as the original authors and source are cited.

How to cite this article: Kalola J, Trivedi A, Happani H, Chauhan M. Lung Manifestation of Collagen Vascular Disease in HRCT. Asian J. Med. Radiol. Res. 2020;8(1):9-13.

DOI: dx.doi.org/10.47009/ajmrr.2020.8.1.2

Source of Support: Nil, Conflict of Interest: None declared.

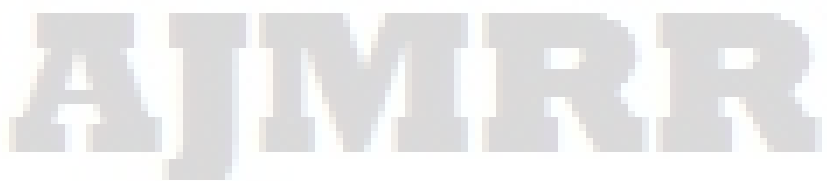

